\title{
Clifford J. Earle: A Life in Mathematics and Music (1935-2017)
}

\author{
Linda Keen and Irwin Kra
}

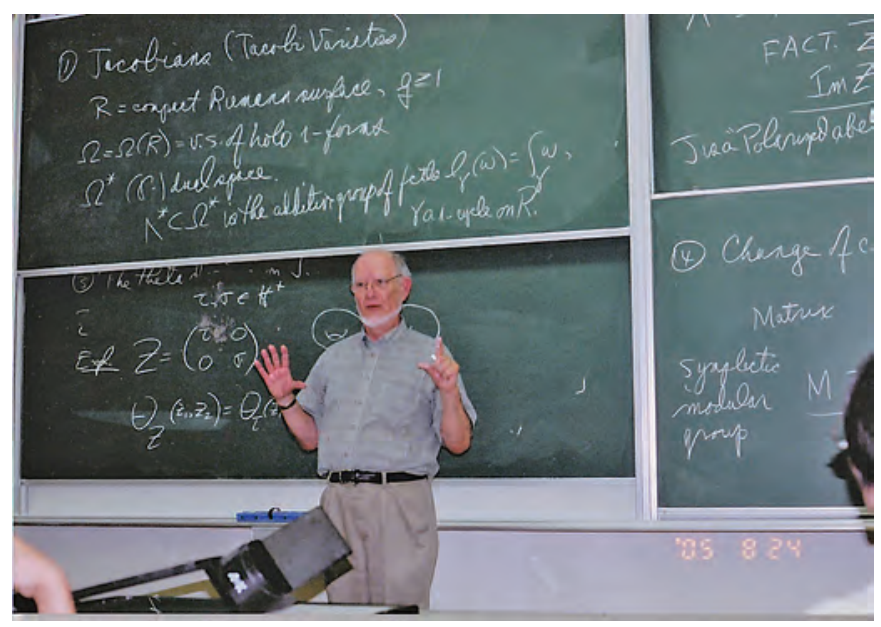

Figure 1. Clifford Earle.

Clifford J. Earle worked in complex analysis and Teichmüller space during his nearly forty years at Cornell. He earned his PhD under Lars Ahlfors at Harvard. In his first position at the Institute for Advanced Study, he persuaded Ahlfors that a set of his lecture notes should be published and undertook to turn them into publishable form. The resulting volume, Lectures of Quasiconformal Mappings [1], remains the standard introductory monograph for the field.

The 1950s and 1960s were a great time to be a graduate student in mathematics in the fields of Riemann surfaces and Teichmüller theory because they were undergoing a rebirth. Ahlfors and Lipman Bers had just proved what is now called the Measurable Riemann Mapping Theorem and Ahlfors was working on his Finiteness Theorem for

Linda Keen is professor emerita at the CUNY Graduate Center. Her email address is 1 inda.keenbrezin@gmai 1.com. Irwin Kra is Distinguished Service Professor Emeritus at SUNY Stony Brook. His email address is i rwinkra@gmai 1 .com.

For permission to reprint this article, please contact: reprint-permission@ams .org.

DOI: http://dx.doi.org/10.1090/noti1613
Kleinian Groups, the most significant result on Kleinian groups in the twentieth century. It made it possible to develop the different structures of finitely generated Kleinian groups and to study various boundaries of moduli spaces. There was excitement in the air and rapid progress because so many people, including those from other fields, were attracted to it. Among these were Dennis Sullivan and William Thurston, who created a second revolution in the field. Sullivan gave a new proof of the Ahlfors Finiteness Theorem, realized that its proof also proves the No-wandering Domain Theorem in complex dynamics, and created a dictionary between Kleinian groups and complex dynamics. Thurston used Kleinian groups to develop his theory of hyperbolic three manifolds.

A Riemann surface is a topological surface with a conformal structure. Teichmüller theory provides a way to distinguish distinct conformal structures that occur with a given topology. Cliff's thesis and a lot of his later work dealt with describing natural families of Riemann surfaces and providing moduli for the members that fit together as a pleasing whole "moduli space." A particular approach to this problem, developed by Earle and his co-authors, was via vector bundles over the moduli spaces.

Among Earle's major contributions, we mention only three of the most influential. These were all joint work: first with James Eells in developing a differential geometric approach to Teichmüller theory [2]; second, his decades' long collaboration with Albert Marden on intrinsic coordinates for moduli spaces; and third, his work with Douady on conformally natural extensions of homeomorphisms of the circle.

Over his long career Cliff collaborated with almost twenty others. It was a pleasure to write a paper with Earle. He was always generous in attributions to others. According to Marden, Cliff had the patience and fortitude to carefully study a situation before putting it in print. And then what he wrote, by himself or with others, was carefully presented. His exposition was clear and got to the key points in a very expeditious manner. Most co-au- 
thors counted on him to provide the final version of a manuscript.

He was also very much a scholar. David Drasin, who knew Cliff at Cornell as a graduate student and remained in touch over many years, remembers Cliff having huge sets of handwritten notes in his office on whatever interested in him in mathematics. Bernard Maskit (Figure 2) recalls that "though our work was disparate, it was always a great pleasure to talk to him, both to listen to his carefully thought out ideas and work, and to have him carefully listen to my explanations of my own work." A long-time friend, Maskit found Cliff's decency and steadiness a great help during a rocky period in his life.

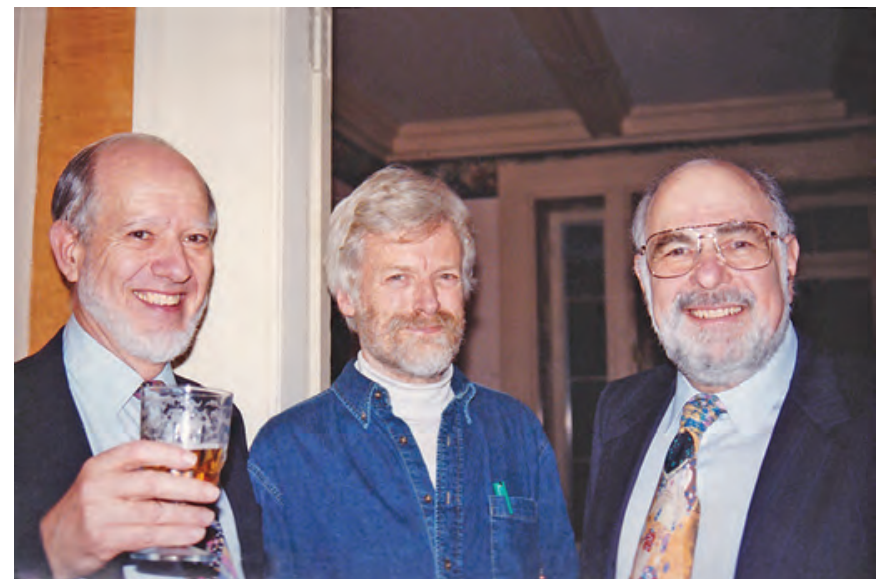

Figure 2. Earle with Bill Harvey and Bernie Maskit.

Cliff was an influential teacher. Benson Farb, who was an undergraduate at Cornell, relates this story about Cliff's graduate student days:

"I still tell the story, about twice each year, that Professor Earle told me about his time at Harvard. He arrived ready to do real analysis, but then flunked

He also took his role as citizen of the mathematical

$$
\begin{gathered}
\text { community very } \\
\text { seriously. }
\end{gathered}
$$

community very seriously. At Cornell he served as chair and on many committees over his long career. He served on the editorial boards of a number of journals and as managing editor of the Proceedings of the AMS. He was part of the committee that restructured its editorial board. He brought his strong sense of integrity to these roles.

Earle's passion for mathematics was matched by his love of music. He was a serious amateur pianist and performed at many venues in Ithaca and particularly enjoyed accompanying singers. He was especially proud of his performance, with tenor Doug Alfors, of the Schubert song cycles.

In sum, Cliff was a man of great integrity and many talents, and a warm personal friend.

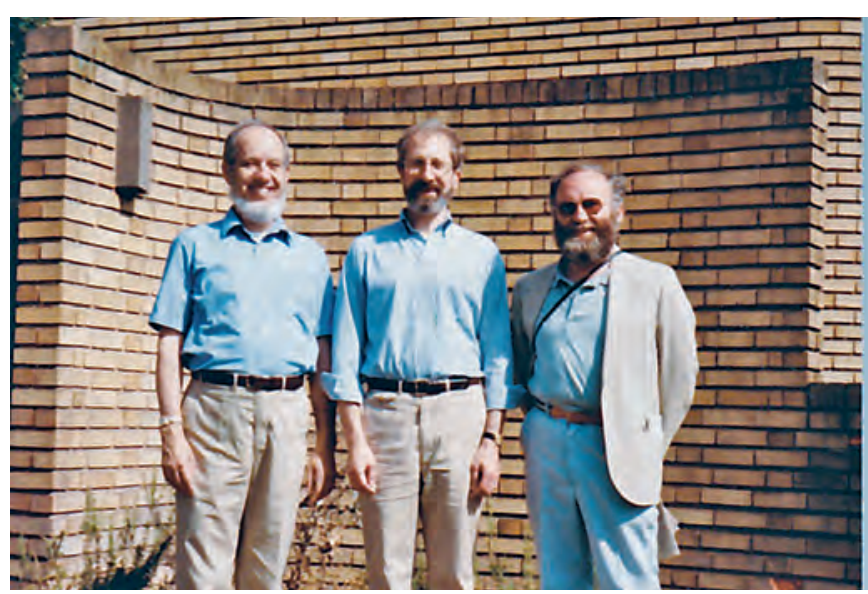

Figure 3. Earle with Albert Marden and Irwin Kra, who was proud to have Earle succeed him as managing editor of PAMS.

\section{References}

[1] L. V. AHLFORS, Lectures on Quasiconformal Mappings, Second Edition, University Lecture Series, vol. 38, Amer. Math. Soc., 2006.

[2] C. J. EARLE AND JR. J. Eells, On the differential geometry of Teichmüller spaces, J. Analyse Math. 19 (1967).

Photo Credits

Figures 1-3 courtesy of Elizabeth D. Earle.
PhD theses and influenced many graduate students and post-docs during his years at Cornell. One of the earliest, Lawrence Harris, wrote about Cliff on the occasion of his 80th birthday:

"Cliff was my thesis advisor during 1966-1969. He gave me many advantages and much to live up to. He shaped how I view mathematical research and what it means to be a mathematician."

Cliff was not only a fine mathematician, scholar, and teacher; he also took his role as citizen of the mathematical 